\title{
What did the public think of health services reform in Bangladesh? Three national community-based surveys 1999-2003 Anne Cockcroft ${ }^{1}$, Neil Andersson*2, Deborah Milne ${ }^{1}$, Md Zakir Hossain ${ }^{3}$ and Enamul Karim 4
}

Address: ${ }^{1}$ CIETcanada, 319-1 Stewart Street, Ottawa, ON, K1N 6N5, Canada, ${ }^{2}$ Centro de Investigación de Enfermedades Tropicales, Universidad Autónoma de Guerrero, Apdo 82, Acapulco, Mexico, ${ }^{3}$ Planning Unit, Directorate of Health Services, Dhaka, Bangladesh and ${ }^{4}$ Health and Life Sciences Partnership, 5-23 Old Street, London EC1V 9HL, UK

Email: Anne Cockcroft - acockcroft@ciet.org; Neil Andersson* - neil@ciet.org; Deborah Milne - dmilne@ciet.org; Md Zakir Hossain - zakirhossain@hotmail.com; Enamul Karim - enamul.karim@hlspworldwide.org

* Corresponding author

Published: 26 February 2007

Health Research Policy and Systems 2007, 5:I doi:10.1 I86/1478-4505-5-1
Received: 24 August 2006

Accepted: 26 February 2007

This article is available from: http://www.health-policy-systems.com/content/5/I/I

(c) 2007 Cockcroft et al; licensee BioMed Central Ltd.

This is an Open Access article distributed under the terms of the Creative Commons Attribution License (http://creativecommons.org/licenses/by/2.0), which permits unrestricted use, distribution, and reproduction in any medium, provided the original work is properly cited.

\begin{abstract}
Background: Supported by development partners, the Government of Bangladesh carried out a comprehensive reform of health services in Bangladesh between 1998 and 2003, intended to make services more responsive to public needs: the Health and Population Sector Programme (HPSP). They commissioned a series of surveys of the public, as part of evaluation of the HPSP. This article uses the survey findings to examine the changes in public opinions, use and experience of health services in the period of the HPSP.
\end{abstract}

Methods: We carried out three household surveys (1999, 2000 and 2003) of a stratified random sample of 217 rural sites and 30 urban sites. Each site comprised 100-120 contiguous households. Each survey included interviews with 25,000 household respondents and managers of health facilities serving the sites, and gender-stratified focus groups in each site. We measured: household ratings of government health services; reported use of services in the preceding month; unmet need for health care; user reports of waiting times, payments, explanations of condition, availability of prescribed medicines, and satisfaction with service providers.

Results: Public rating of government health services as "good" fell from $37 \%$ to $10 \%$ and the proportion using government treatment services fell from $13 \%$ to $10 \%$. Unmet need increased from $3 \%$ to $9 \%$ of households. The proportion of visits to government facilities fell from $17 \%$ to $13 \%$, while the proportion to unqualified practitioners rose from $52 \%$ to $60 \%$. Satisfaction with service providers' behaviour dropped from $66 \%$ to $56 \%$. Users were more satisfied when waiting time was shorter, prescribed medicines were available, and they received explanations of their condition.

Conclusion: Services have retracted despite increased investment and the public now prefer unqualified practitioners over government services. Public opinion of government health services has deteriorated and the reforms have not specifically helped the poorest people. User satisfaction could be increased if government doctors improved their interaction with patients and if waiting times were reduced by better management of facilities. 


\section{Background}

The Bangladesh Health and Population Sector Programme (HPSP) 1998-2003 [1,2] explicitly aimed to achieve a more client-centred service, more responsive to the needs of the very poor and women. Amongst other reforms, a key element of the HPSP was unification of health and family planning services, until then covered by separate wings of the Ministry of Health and Family Welfare and operating independently on the ground. Another important aspect was construction of a large number of community clinics so that services would be provided from these clinics rather than by home visits from community health and family planning workers.

The HPSP was not fully implemented as intended. The problems are reviewed in the World Bank Implementation, Completion and Results (ICR) report for the HPSP project, in which the World Bank played a lead role in the consortium of development partners [3]. According to the ICR report, which rated the overall project outcome as 'unsatisfactory', the unification of health and family planning services had negative consequences because of the disruption it caused. Although supported at local level, unification was resisted from the beginning at district level and above. In 2001, the national government changed and the unification was halted, and reversed formally in 2003 [4]. The new government after 2001 also halted the programme of constructing community clinics and re-instituted home visits; even before this many of the clinics had not become operational as quickly as intended $[5,6]$.

As well as undertaking internal reviews of status of performance indicators [7] and using information about health status during the period from DHS surveys [8-10], the government and development partners commissioned a series of three community-based surveys as part of the HPSP programme monitoring and evaluation. The surveys measured public perceptions and use of government services, and the satisfaction of service users, and included an analysis of factors related to better public experiences and views, as an aid to future programme planning [11-13].

A review of methods to incorporate patient views concluded that efforts to improve health care must reflect what patients want from the service [14]. Most approaches to eliciting patient views of the health services rely on contacting patients at the health facilities [15] or after they leave [16]. Contacting patients at their home addresses introduces important biases $[17,18]$, even with reliable postal and telephone services, and is not feasible in most developing countries. Even if one could contact them all, limiting consultation to patients and ex-patients excludes the views of people who do not use the services, even though they may need them. Therefore the surveys in Bangladesh were community based and included the views of people who did not use government health services as well as those who did use them.

In this paper we draw on findings from the three surveys to review the changes in public views, use and experiences of government health services during the period of the HPSP and comment on indications from the findings about what might help to increase public use of and satisfaction with government health services in the future.

\section{Methods}

The project, including the three community surveys described in this paper, was reviewed and approved by the CIETinternational ethical review panel prior to the first survey in 1999.

In the mid-1980s, CIET developed methods to build local measurement capacities while producing accurate and actionable data rapidly and at low cost $[19,20]$. The approach combines quantitative household data with coterminous data from the survey sites, including data from facilities and qualitative data from focus groups, to identify potentially effective interventions $[21,22]$. In Bangladesh, three survey cycles used this approach in linked samples. The first cycle in 1999 provided a baseline, while the second (2000) and third (2003) updated information on the public use, perception and experiences of health and family planning services. The Ministry of Health and Family Welfare, the bureau of statistics and local researchers participated in the design of the surveys.

A two stage stratified random sample of villages was selected within each of the six divisions, with the number of villages proportional to the population of the division. In each of the 44 selected upazilas (administrative areas of 2-300,000 people) we selected five (in three cases, four) villages randomly, giving a total of 217 villages. In each village, we selected $100-120$ contiguous households radiating from a random starting point. A further random sample of 30 enumeration areas was drawn from the main cities in the country, the number in each city proportional to the population. The 2000 and 2003 surveys used the 1999 sample, but with a random $25 \%$ of the rural sites reselected.

The household questionnaire asked about perceptions, use and experience of health and family planning services from different providers. It was translated into Bengali, pre-tested and adjusted. For each cycle, we trained 15 teams of interviewers in four regional centres. Divisional coordinators monitored the fieldwork. The field teams also visited the upazila health facilities serving each sample community and interviewed the heads of the facilities, 
collecting information about the medicines, amenities, and equipment available, and the way the facilities were run. Following entry and preliminary analysis of the data from households, trained field teams returned to the survey sites to discuss findings in gender stratified focus groups.

We used Epi Info [23] for double data entry and validation. We defined the poorest households as those below the 25th percentile of reported household income. Unmet need for health care was a household reporting at least one member ill in the last month but having no contact with any health service in this time. We examined univariate associations, calculating the Odds Ratio and 95\% confidence interval, and examined the simultaneous effects of variables by logistic regression [24], from which we derived adjusted Odds Ratios and calculated adjusted Risk Differences.

\section{Results}

Some $47 \%$ of the household heads were literate in 1999 and 2000, increasing to $50 \%$ in 2003. Most household respondents were female in all three surveys $(22,350$ / 25,490 or $88 \%$ in 2003 ).

\section{Household opinions of government and private health and family planning services}

The proportion rating the services as 'good' fell from 39\% in 1999 to $10 \%$ in 2000 (OR 5.74, 95\%CI 5.47-6.03; $9,836 / 25,518$ in 1999 , compared with $2,467 / 25,053$ in 2000) and remained about the same in 2003.

We examined possible causes for the decline in public opinion in a multivariate model (Table 1). Sex and economic status of the respondent were related to rating in each cycle but they did not explain deterioration in the rating between cycles. The decline in opinion was less marked in households who reported use of the services in 2003 and in households with an illiterate head. It was also less marked in communities where the review of the local health facility revealed it to be more "user-friendly" (for example had screens for privacy or had toilets for women) and in communities where the health facility head reported there was an active health services development committee involving the public. However, most of the difference in public opinion between 1999 and 2003 was not explained by the factors examined.

Rating of government services, when few households use these services themselves (see below) was probably influenced by past experience, hearsay evidence from friends and neighbours, and media coverage. There was some change in the pattern of perceived problems with the services across the three cycles (Table 2). Lack of medicines was the most common complaint throughout. Bad atti- tude of staff was more commonly mentioned in 2000 and 2003, as were extra payments to doctors. Focus group participants echoed these complaints from the household respondents and described them more fully, making it clear that government health services had a very bad reputation with the public.

\section{Use of health and family planning services}

Only $15 \%$ of visits to health and family planning services were for preventive purposes and these are not considered further here.

Between 1999 and 2003 there was a decrease from 13\% to $10 \%$ in the proportion of households who reported at least one member using government health services for treatment in the preceding month $(3,405 / 26,207$ in 1999 compared with 2,516/25,487 in 2003; OR 1.36, 95\%CI $1.29-1.44)$. During the same period there was an increase from $30 \%$ to $49 \%$ in the proportion of households who reported using private services (including unqualified practitioners) for treatment in the preceding month $(7,752 / 26,158$ in 1999 compared with $12,574 / 25,488$ in 2003; OR 0.43, 95\%CI 0.42-0.45).

Focus group participants gave insights into why people choose alternatives to government health services, with comments such as "most of the time we don't find any doctors in government facilities, so we turn to the village doctors" and "the village doctors would come at midnight if they are called".

In $19993 \%$ (778/26158) of households had unmet need for health care. Unmet need was higher in 2000 at $11 \%$ (2892/25468) and in 2003 at $9 \%(2406 / 25475)$, with a significant decrease between 1999 and 2003 (OR 3.40, 95\%CI 3.13-3.70). Both the 1999 and 2003 surveys were conducted in January-February, so seasonal variation cannot explain the increase in unmet need. In 2003, unmet need was more likely if the household head was female or illiterate, in rural sites and in the poorest households. These personal variables remained in a multivariate model of unmet need in 1999 and 2003, but did not explain much of the increase in unmet need between 1999 and 2003 (Table 3).

\section{Experience and satisfaction of users of health services}

Among reported outpatient visits (there were less than 5\% admissions) to health services for treatment in the preceding month, the share going to government facilities fell from $17 \%(2,575 / 14,614)$ in 2000 to $13 \%(2,231 /$ 17,514 ) in 2003 (OR $1.44,96 \% \mathrm{CI} 1.36-1.54$ ), while the share using unqualified practitioners rose from $52 \%$ $(7,633 / 14,614)$ to $60 \%(10,564 / 17,514)$ (OR 0.72 , $95 \%$ CI $0.69-0.75$ ). Most (43\% of all visits) of the unqualified (non-medically qualified) practitioners were village 
Table I: Final model of factors influencing general opinion of respondents, contrasting 1999 with 2003

\begin{tabular}{|c|c|c|c|c|}
\hline & Crude OR & Adjusted OR & $95 \% \mathrm{Cl}$ adjusted $\mathrm{OR}$ & $\chi^{2} \mathrm{mh}$ \\
\hline Head of household illiterate 2003 & 0.89 & 0.83 & $0.78-0.89$ & 26.9 \\
\hline Someone in household used govt health in last month 2003 & 0.83 & 0.92 & $0.85-0.99$ & 4.1 \\
\hline Either UHC or UHFWC had curtains for examinations 1999 & 0.69 & 0.66 & $0.6 \mathrm{I}-0.73$ & 76.85 \\
\hline Either UHC or UHFWC had separate toilet for women 1999 & 0.78 & 0.77 & $0.68-0.87$ & 17.36 \\
\hline Upazila health service development committee present 2003 & 1.01 & 0.89 & $0.82-0.96$ & 10.08 \\
\hline Unexplained difference between 1999-2003 & 4.95 & 4.97 & $4.62-5.34$ & 1000.1 \\
\hline
\end{tabular}

OR = Odds Ratio

UHC = Upazila health centre

UHFWC = Union health and family welfare centre (more local facility).

doctors or "quacks", many of whom had received some paramedical training.

Between 2000 and 2003 there was a significant decrease from $66 \%(1,591 / 2,415)$ to $56 \%(1,257 / 2,230)$ in the proportion of users of government services who were satisfied with the way the service providers behaved towards them (OR 1.49, 95\%CI 1.32-1.69). Satisfaction with the behaviour of private and unqualified providers was higher (over 90\%) and did not change between 2000 and 2003.

Patients were much more likely to be satisfied with private or unqualified providers than with government providers in 2003 (OR 7.39, 95\%CI 6.67-8.18).

Half of government service users in 2000 (50\%; 1,196) $2,411)$ felt they had a full explanation of their condition compared with 44\% $(981 / 2,230)$ in 2003 (OR 1.25, 95\%CI 1.11-1.41). In 2003, service users who considered they had a full explanation of their condition were much more likely to report satisfaction with the behaviour of the service provider $(85 \%, 809 / 981)$ compared with those who did not consider they had a full explanation (36\%, $448 / 1,249$ ) (OR 8.29, 95\%CI 6.78-10.14). This association was mainly among users from households with an income at or above the $25^{\text {th }}$ percentile: $84 \%$ (661/787) of those with an explanation were satisfied compared with $36 \%(330 / 917)$ of those without an explanation (OR 9.3, 95\% CI 7.32-11.9).

One third of government service users in 1999 (33\%, 866/ $2,641)$ reported all the prescribed medicines were available to them from the facility compared with only $23 \%$ $(435 / 1920)$ in 2003 (OR 1.67, 95\%CI 1.45-1.91). In 2003, service users who got all the prescribed medicines from the facility were more likely to be satisfied with the behaviour of the service provider $(79 \%$; 343/435) compared with those who did not get all the prescribed medicines (53\%; 783/1,485) (OR 3.34, 95\%CI 2.57-4.35). Focus group participants blamed health workers for the failure of government facilities to provide the prescribed medicines, with comments such as "the health workers only give medicines to known people; they don't give them to the poor" and "the government supplies medicine to the facilities, but we don't get them."

Waiting times in government facilities changed little between 2000 and 2003 (median 30 minutes). In 2003, service users who waited less than 30 minutes to be attended were more likely to be satisfied with the behav-

Table 2: Identified problems in government health and family planning services

\begin{tabular}{llll}
\hline & \% (No) of respondents & 2003 \\
\hline Identified problems & 1999 & 2000 & $55(14,052)$ \\
\hline Lack of/poor quality of medicines & $54(14,128)$ & $58(14,621)$ & $29(7,447)$ \\
Bad staff attitude & $15(4,015)$ & $25(6,276)$ & $27(6,75 I)$ \\
Bad service & $29(7,561)$ & $40(10,098)$ & $17(4,440)$ \\
Extra payment to doctors & $9(2,376)$ & $12(3,091)$ & $17(4,379)$ \\
Have to pay for medicines & $9(2,202)$ & $17(4,263)$ & $16(4,164)$ \\
Difficult to reach & $22(5,588)$ & $19(4,785)$ & $15(3,887)$ \\
Doctors not available & $7(1,876)$ & $13(3,178)$ & $11(2,887)$ \\
Dirty, poor equipment/facilities & $15(3,984)$ & $13(3,399)$ & $10(2,618)$ \\
Lack of doctors/specialists/nurses & $18(4,698)$ & $14(3,561)$ & $10(2,600)$ \\
Lack of different services & $6(1,481)$ & $14(3,478)$ & $1(338)$ \\
No problem & $6(1,679)$ & $1(238)$ & $7(1,706)$ \\
Too few beds/lack of facilities & $7(1,833)$ & $7(1,886)$ &
\end{tabular}


Table 3: Actionable factors influencing report of unmet need (households with someone ill who did not seek medical attention) in 1999 and 2003 (n5 1633)

\begin{tabular}{lccccc}
\hline & Crude OR & Adjusted OR & 95\%Cl adjusted OR & Adjusted gain/I000 & 95\%Cl gain \\
\hline Illiterate head of household & 1.43 & 1.35 & $1.25-1.46$ & 12.7 & $9.56-15.9$ \\
Female headed household & 1.87 & 1.50 & $1.34-1.69$ & $1.7-3.1$ & 2.4 \\
Rural resident & 1.56 & 1.39 & $1.22-1.59$ & 9.2 & $5.5-13.0$ \\
Poorer household (lowest 25 percentile 2003) & 0.96 & 1.14 & $1.04-1.24$ & $0.7-3.4$ & 2.0 \\
Unexplained difference between 2003 and 1999 & 3.41 & 3.48 & $3.2-3.77$ & 36.8 & $34.5-39.2$
\end{tabular}

I. The individual benefit is the adjusted Odds Ratio from logistic regression.

2. The PRI (proportion requiring intervention) is the proportion of service users who currently do not have the favourable value of the variable. For example, the proportion that currently does not get all the prescribed medicines is $80 \%$.

3. The gain per 1000 is calculated by multiplying the PRI by the risk difference. This is the proportion who could potentially become satisfied with the service as a result of each intervention.

iour of the service provider (59\%; 875/1,475) compared with those who waited longer $(50 \% ; 382 / 771)$ (OR 1.53, $95 \%$ CI $1.28-1.84$ ).

Around $20 \%$ of government service users reported making unofficial direct payments to service workers, with little change in this proportion over time $(21 \%, 20 \%$, and $18 \%$ in 1999, 2000 and 2003 respectively). Making these payments made no difference to reported satisfaction with the behaviour of the service providers.

We examined the factors associated with satisfaction with government service providers in a multivariate model to examine the reduction in satisfaction between 2000 and 2003. The model excludes the small group of users who made no payment at all for their visit. Table 4 shows the theoretical impact of strategies to improve satisfaction. Some decline in satisfaction remains to be explained (bottom row in Table 4), but there is a sizeable potential impact from changing the way doctors interact with patients, reducing waiting times, and making all prescribed medicines available.

\section{Discussion}

Satisfaction is a capacious concept, heavily conditioned by culture, expectations and sense of entitlement $[25,26]$.
Most people in Bangladesh have fairly low expectations of their health services [27]. Given that the survey was repeated in the same places between 1999 and 2003, "cultural" influences on satisfaction are likely to have remained more or less constant, so reductions in reported satisfaction over this relatively short period are a legitimate cause for concern. However, we recognise that extraneous factors such as political unrest might have undermined trust in public services generally during the period.

Increasing dissatisfaction of public and service users was accompanied by decreasing use of government health services and increase in the unmet need for health care. Taken together, this represents effective retraction of the health services, despite the large financial investment in the HPSP (over US \$ 350 million from development partners between 1999 and 2005 [3]). This retraction seems to have been felt disproportionately by the vulnerable; households headed by illiterate and female heads, those in rural areas and those in the lowest $25 \%$ of income all were more likely to have unmet need in 2003 compared with 1999.

The three surveys reported here agree with other studies from Bangladesh. Lack of medicines in government health

Table 4: Actionable factors influencing satisfaction with behaviour of health workers, among those who used services in 2000 and 2003 : Gains from different strategies $(n=4 \mid 28)$

\begin{tabular}{llllll}
\hline & Crude OR & Adjusted OR & $95 \% \mathrm{Cl}$ adjusted OR & Adjusted gain/I000 & $95 \% \mathrm{Cl}$ gain \\
\hline Illiterate head of household & 0.59 & 0.72 & $0.61-0.84$ & 2.4 & $1.3-3.5$ \\
Waiting time under 20 minutes & 2.11 & 1.81 & $1.53-2.14$ & 61.4 & $94.1-78.6$ \\
Received all prescribed drugs & 3.73 & 2.29 & $1.84-2.85$ & 96.3 & $70.8-121.8$ \\
Received explanation about illness & 10.41 & 2.89 & $2.3-3.63$ & 91.6 & $72.1-111.2$ \\
Received explanation about remedy & 10.7 & 4.61 & $3.37-5.69$ & 154.8 & $133.5-176.2$ \\
Unexplained difference between 2003 and 2000 & 1.54 & 1.81 & $1.54-2.11$ & 34.8 & $25.6-44.1$ \\
\hline
\end{tabular}

I. The individual benefit is the adjusted Odds Ratio from logistic regression.

2. The PRI (proportion requiring intervention) is the proportion of service users who currently do not have the favourable value of the variable. For example, the proportion that currently does not get all the prescribed medicines is $80 \%$.

3. The gain per 1000 is calculated by multiplying the PRI by the risk difference. This is the proportion who could potentially become satisfied with the service as a result of each intervention. 
facilities was a frequent complaint of service users in Dhaka [28]. The 2001 Bangladesh Health and Demographic Survey [8] reported $50 \%$ of people used an unqualified doctor for treatment of illness, $17 \%$ used a private pharmacy, and only $13 \%$ saw a doctor in a government facility. A 2003 survey of government health facilities reported many unfilled posts for service providers and that many doctors were absent from the facilities at the time of unannounced visits [29].

It would be misleading to suggest that any single or simple intervention will reverse this complex situation. The surveys did offer indications of the possible magnitude of benefits of interventions to improve satisfaction of service users. A low cost intervention to improve user satisfaction would be to give patients explanations of their condition and treatment. The challenge is to persuade government doctors to talk to patients. The doctors can do this, given the right environment: in most rural areas, the government doctors are the same individuals that, seen privately, patients are mostly satisfied with and feel they have had an explanation from.

Improved management, including filling vacant posts and ensuring doctors and other service providers attend regularly, could reduce waiting times. The cost of ensuring regular medical attendance would depend on the measures adopted to achieve it. Increasing salaries would be expensive. Ensuring all prescribed medicines are available would increase the number of satisfied users, but it would be costly and is a longer-term initiative.

Improving the experience of service users may help to reverse the drift away from government services. When asked how they would persuade people to use government health services, focus group participants explained that once the quality improved, people would naturally use the services: "Why do people come to a tea stall? Because the shopkeeper behaves well and the tea tastes good."

\section{Conclusion}

From the point of view of the public, government health services retracted during the period of the HPSP despite increased investment and the public now prefer unqualified practitioners over government services. Public opinion of government health services has deteriorated and the reforms have not specifically helped the poorest people. Analysis based on the survey findings suggests that user satisfaction with government health services could be increased relatively quickly if government doctors improved their interaction with patients and if waiting times were reduced, for example by better management of facilities.

\section{Competing interests}

The author(s) declare that they have no competing interests.

\section{Authors' contributions}

AC helped design the study, led the implementation of all three surveys, undertook the analysis, and drafted this manuscript. NA designed the study, advised on analysis, and reviewed the draft manuscript. DM, ZH and EK supported implementation of the surveys and helped with analysis. All authors read and approved the final manuscript.

\section{Acknowledgements}

The third social audit cycle was conducted in collaboration with several Bangladeshi institutions: the National Institute of Preventive and Social Medicine (NIPSOM), the National Institute of Population Research and Training (NIPORT) and the Institute of Epidemiology, Disease Control and Research (IEDCR). Each institution nominated participants for design and quality control. Each of the three cycles was led by a technical steering group, chaired by the Joint Chief (Planning), MOHFW. We are grateful to many colleagues in Bangladesh who contributed to the instrument design, data collection and data entry as well as to discussions about the findings. We are especially grateful to the thousands of men and women across Bangladesh who took time away from their work of daily living to respond to interviewers and to take part in focus group discussions; and to the service providers who also willingly gave their time to participate in the survey process. The Canadian International Development Agency provided the funding for the three surveys.

\section{References}

I. Ministry of Health and Family Welfare: Health and Population Sector Programme 1998-2003 - Programme Implementation Plan Dhaka, Government of Bangladesh; 1998

2. Vaughan JP, Karim E, Buse K: Health care systems in transition III. Bangladesh, Part I. An overview of the health care system in Bangladesh. J Public Health Medicine 2000, 22:5-9.

3. World Bank: Implementation, Completion and Results (ICR) report. Health and Population Program Project, Bangladesh Washington, World Bank; 2005.

4. Sundewall J, Forsberg BC, Tomson G: Theory and practice - a case study of coordination and owenership in the Bangladesh health SWAp. Health Research Policy and Systems 2006, 4:5.

5. Normand C, Iftekar MHM, Rahman SA: Assessment of the community clinic: effects on service delivery, utilization and quality of services Dhaka, Health Economics Unit, Ministry of Health and Family Welfare; 2002.

6. Mercer A, Huq NL, Hasseen F, Uddin AHN, Reza M: Use of family planning services in the transition to a static clinic system in Bangladesh 1998-2002. International Family Planning Perspectives 2005, $31: 3$.

7. Streatfield PK, Mercer A, Siddique AB, Khan ZUA, Ashraf A: Status of performance indicators 2002 Dhaka, Government of Bangladesh; 2003.

8. National Institute of Population Research and Training (NIPORT), Mitra and Associates, and ORC Macro: Bangladesh Demographic and Health Survey 2001 Dhaka, Bangladesh and Calverton, Maryland [USA]: National Institute of Population Research and Training, Mitra and Associates, and ORC Macro; 2003.

9. National Institute of Population Research and Training (NIPORT), ORC Macro, Johns Hopkins University and ICDDR,B: Bangladesh Maternal Health Services and Maternal Mortality Survey 200I Dhaka, Bangladesh and Calverton, Maryland (USA): NIPORT, ORC Macro, Johns Hopkins University, and ICDDR,B; 2003.

10. National Institute of Population Research and Training (NIPORT), Mitra and Associates, and ORC Macro: Bangladesh Demographic and Health Survey 2004 Dhaka, Bangladesh and Calverton, Maryland [USA]: National Institute of Population Research and Training, Mitra and Associates, and ORC Macro; 2005. 
II. Cockcroft A, Monasta L, Onishi J, Karim E, Andersson N: Bangladesh Health and Population Sector Programme. Baseline service delivery survey, 1999 Dhaka, CIETcanada and Ministry of Health and Family Welfare, Government of Bangladesh; 1999.

12. Cockcroft A, Monasta L, Karim E, Andersson N: Bangladesh Health and Population Sector Programme. Second service delivery survey, 2000 Dhaka., CIETcanada and Ministry of Health and Family Welfare, Government of Bangladesh; 2001.

13. Cockcroft A, Milne D, Andersson N: Bangladesh Health and Population Sector Programme. The third service delivery survey, 2003 Dhaka, CIETcanada and Ministry of Health and Family Welfare, Government of Bangladesh; 2004.

14. Wensing M, Elwyn G: Improving the quality of health care. Methods for incorporating patients' views in health care. $B M$ 2003, 326:877-9.

15. Mullen PM: Public involvement in health care priority setting: an overview of methods for eliciting values. Health Expectations 1999, 2:222-34.

16. Guadagnoli E, Ward P: Patient participation in decision-making. Soc Sci Med 1998, 47:329-39.

17. Etter JF, Perneger TV: Analysis of non-response bias in a mailed health survey. J Clin Epidemiol 1997, 50: I I23-8.

18. Sitzia J: How valid and reliable are patient satisfaction data? An analysis of 195 studies. Int J Qual Health Care 1999, I I:3 19-28.

19. Andersson N: Impact, Coverage and Costs: An operational framework for monitoring child survival emerging from two UNICEF projects in Central America 1985 [http://www.ciet.org]. Guatemala City: UNICEF

20. Andersson N, Martinez E, Cerrato F, Morales E, Ledogar RJ: The Use of Community Based Data in Health Planning in Mexico and Central America. Health Policy and Planning 1989, 4:197-206.

21. Andersson N: Mesoanalysis: Quantifying qualitative data from communities and services. In Evidence based planning: the philosophy and methods of sentinel community surveillance Washington: EDI/ World Bank; 1996.

22. Andersson N, Mitchell S: Epidemiological geomatics in evaluation of mine risk education in Afghanistan: introducing population weighted raster maps. Int J Hlth Geographics 2006, 5: I.

23. Epi Info: A word-processing, database and statistics system for epidemiology on microcomputers Epidemiology program office, Centers for Disease Control and Prevention, Atlanta, USA. Version 6; 1994.

24. Statistical Package for the Social Sciences SPSS Inc. Chicago, Illinois, USA.

25. Williams B: Patient satisfaction: a valid concept? Soc Sci Med 1994, 38:509-16.

26. Rubin HR: Can patients evaluate the quality of hospital care? Med Care Rev 1990, 47:267-325.

27. Chakraborty N, Ataharul MI, Chowdhury RI, Bari W, Akhter $\mathrm{HH}$ : Determinants of the use of maternal health services in rural Bangladesh. Health Promotion International 2003, I 8:327-337.

28. Khatun J, Roy NC, Azim T: Unmet reproductive and child-health needs and use of Essential Services Package in urban NGO clinics of Bangladesh 2003 [http://202.136.7.26/pub/publication.jsp?pubID=4382] ICDDR,B WPI56 24th January 2004

29. Chaudhury N, Hammer JS: Ghost doctors: absenteeism in Bangladesh health facilities World Bank Policy Research Working Paper 3065 Washington, World Bank; 2003.

\section{Publish with Bio Med Central and every} scientist can read your work free of charge

"BioMed Central will be the most significant development for disseminating the results of biomedical research in our lifetime. "

Sir Paul Nurse, Cancer Research UK

Your research papers will be:

- available free of charge to the entire biomedical community

- peer reviewed and published immediately upon acceptance

- cited in PubMed and archived on PubMed Central

- yours - you keep the copyright
BioMedcentral 